\title{
Teknokultura
}

ISSNe: 1549-2230

http://dx.doi.org/10.5209/TEKN.59724

\section{Construcción de la identidad digital a través del yo-objeto: proceso de auto-objetivación y su relación con la cosificación del cuerpo de las mujeres}

\author{
Estela Santos Díaz ${ }^{1}$
}

Recibido: 27 de marzo de 2018 / Revisado: 19 de junio 2018 / Aceptado: 26 de junio de 2018 Open peer reviews

Resumen. En el proceso de construcción de la identidad digital, esta se asocia a una transformación de objetivación del yo que implica el desarrollo de una visión auto-objetivadora a la vez que cosificadora de los otros digitales. Este texto ofrece una breve reflexión sobre la proyección digital de la identidad individual y colectiva. Para ello se expondrán las distintas interpretaciones teóricas que han abordado este concepto. Asimismo, se examinarán las implicaciones que tiene esta objetivación de los individuos en la reformulación digital de la identidad femenina.

Palabras clave: auto-objetivación; cosificación de la mujer; identidad virtual; identidad femenina; prosumidor.

\section{[en] Digital identity construction through self-objectification: creation of the self-object and its relation with women's bodies objectification}

\begin{abstract}
In the context of digital identity, the construction process is related to an objectifying transformation of the self. This implies the development of a self-objectifying perception, and simultaneously an objectifying vision of the digital others. This article offers a brief reflection on digital projection of individual and collective identities, overviewing the different theoretical interpretations that have studied this concept. Furthermore, the implication of feminine objectification will be explored.
\end{abstract}

Keywords: digital identity; feminine identity; prosumer; self-objectification; women's objectification.

Sumario. 1. Introducción. 2. Acercándonos a una teoría de la identidad digital. 3. La producción y el consumo de contenido digital como intercambio identitario. 4. El Yo-objeto y su relación con la objetualización de la mujer. 5. Conclusiones. 6. Referencias.

Cómo citar: Santos Díaz, E. (2018). Construcción de la identidad digital a través del yo-objeto: proceso de auto-objetivación y su relación con la cosificación del cuerpo de las mujeres, en Teknokultura 15(2), 301-309.

\footnotetext{
1 Universidad Rey Juan Carlos (España)

email: estela.santos.diaz@gmail.com
} 


\section{Introducción}

En los últimos años de producción científica en ciencias sociales han proliferado los estudios acerca del mundo digital y, principalmente, de las redes sociales digitales, visto aquel como un campo de interés científico ante la posibilidad de estudiar las nuevas formas de interacción interpersonal.

Por lo general, la idea subyacente a la conceptualización sobre la identidad digital es la expresión de rasgos característicos del yo a través de medios de comunicación digital (Fernández, 2012). Uno de los rasgos que más inquietud causa entre los autores que han investigado esta temática son las implicaciones sociales e individuales que tiene esta forma de expresión identitaria. La digitalización del yo implica, tácitamente, una compresión de los rasgos que nos caracterizan y, como consecuencia, resulta en la construcción de un yo objeto que nos representa en el espacio digital.

El objetivo de este artículo es mostrar los diferentes puntos de vista teóricos desde los que se ha estudiado este fenómeno reciente desde un posicionamiento crítico. A su vez se busca profundizar en el impacto que esta creación del yo puede causar en la formulación de la identidad colectiva. Se pondrá el foco en la identidad de género, y no en otras identidades colectivas troncales, debido a que la identidad de género estructura la vida de los individuos desde su nacimiento. Esta identidad se erige bajo la idea fundamental de que las personas se distribuyen en grupos sociales con características y roles conductuales categóricos, fuertemente distintivos e inherentes a su ser establecidos a raíz de la división sexual y la correspondiente adscripción a un género u otro (Hernando, 2012). Por este motivo es significativo analizar cómo la identidad de género es representada en el mundo digital. Se hace especialmente relevante reflexionar sobre las consecuencias que puede tener para la identidad femenina, entendida como vivencia colectiva, la creación de un yo objeto en las mujeres, ya que la objetualización para las mujeres ha sido un fenómeno con implicaciones patriarcales.

\section{Acercándonos a una teoría de la identidad digital}

Los procesos de interiorización y elaboración de una identidad individual y compleja en las personas ha cambiado con la fuerte colectivización del acceso a la información personal. Esto ha supuesto la conexión online a partir de finales de la década de los 90 y principios del s. XXI, y ha generado cambios intrínsecos en las personas y en las relaciones interpersonales. Digitalizando el proceso identitario se produce un efecto de auto-objetualización en Internet mediante el cual los usuarios conceptualizan sus intervenciones y datos publicados en la red como aglutinantes de un "yo" cosificado que se puede modificar e intercambiar para conseguir unos objetivos marcados por el propio usuario (Fernández, 2012). El concepto de identidad digital, a pesar de ser relativamente novedoso, ha sido abordado en la literatura científica a partir de diferentes perspectivas. Cuando se menciona la identidad digital, se puede hacer referencia a dos aspectos diferentes: uno basado en lo tangible material y otro fundamentado en la autoadscripción.

El más tangible lo forman los datos personales que introducimos en el mundo online y que nos identifican instrumentalmente: los datos bancarios, contraseñas, fechas de nacimiento o códigos. Estos datos pueden facilitar la monitorización o la extracción 
de información del individuo por parte de terceros (Fernández, 2012). Las líneas de investigación que parten desde este punto se centran en los usos que se le puede dar a este tipo de informaciones y medidas de protección personal, o la construcción de espacios libres de monitorización y/o rastreo de información personal.

El otro aspecto mencionado es el yo autorrepresentativo que se da en algunos espacios online como, y especialmente, en las redes sociales. En estos espacios se generan unas formas del yo autoconstruidas, públicas y gestionadas por el individuo. En las redes sociales se construye un yo objetualizado desde la implicación subjetiva de mostrarnos a los otros sociales (Fernández, 2012). Desde los estudios científicos que trabajan esta perspectiva se ha centrado la atención en la relación del sujeto con la mirada de los otros.

\subsection{La identidad digital desde el paradigma de la identidad social}

La teorización de la identidad digital se ha vinculado con las teorías de las identidades sociales, ya que se cimientan en la importancia de las relaciones y los aprendizajes colectivos en la formación de identidades. La denominada Identity Theory defiende la idea de que el individuo construye su identidad a través de un conjunto de roles sociales que va adquiriendo y reproduciendo durante su historia de vida (Hogg, Terry y White, 1995). A través de los roles adquiridos se construye un yo complejo e integrado en su sistema social. Es una teoría que asienta sus bases en la teoría del interaccionismo simbólico. No obstante, este último analiza las identidades desde una perspectiva sociológica y menos asentada en la psicología. Centra su teorización en el "yo" -o self-compuesto por una amplia variedad de roles sociales y expectativas. Esta teoría sostiene que el enlace entre la identidad y el comportamiento es el lugar en el que se encuentra el sujeto en la estructura social en la que está inmerso y de la que toma estos roles y expectativas sociales (Serpe y Stryker, 2011). La diferencia principal entre la Identity Theory y la teoría del interaccionismo simbólico radica en la importancia que esta última otorga a la interacción entre los diferentes conjuntos sociales para la creación del yo y el hincapié que hace en la significación e interpretación como procesos fundamentales para la creación de un yo coherente dentro de un sistema social. Erving Goffman (1971), desde su interpretación del interaccionismo simbólico, entiende la creación de la identidad individual como un acto dramatúrgico dentro de esta interacción necesaria donde el sujeto se representa a sí mismo en función del escenario donde se encuentre. Esta idea recuerda a interpretaciones posteriores que se han hecho sobre el ámbito digital, ya que es extendida la comprensión del entorno digital como un espacio social con unos códigos con significado propio que son difícilmente descontextualizables del ámbito online.

Con una visión sustancialmente distinta, los autores adscritos a la "Social Identity Theory" interpretan la identidad social como una entidad esencial con significado propio generando categorías identitarias que solamente tienen sentido siendo compartidas en colectividad (Tajfel, 1984). Esta teoría contempla la identidad social como una entidad que no tiene únicamente un carácter descriptivo o sistemático, sino que posee la habilidad de crear valoraciones. La vinculación hacia una identidad o grupo social determinados puede estar ligada a una interpretación positiva que proporcionará autoestima al individuo, siendo una manera de autosignificación positiva en sociedades altamente complejas (Peris y Agut, 2007). 


\subsection{La identidad digital basada en el estudio del medio digital}

Estas teorías están integradas en una comprensión de las identidades sociales como estructuras llenas de significado, relacionada con la identidad teatro de Goffman, mencionada con anterioridad. Cabe destacar la importancia que un gran número de autores le otorgan a la propia estructura digital en la creación de un yo dentro de este ámbito social. Para ello, consideramos reseñable destacar la interpretación de la identidad digital denominada identidad mosaico acuñada por Lucía Caro Castaño (2012). Caro Castaño expone la identidad digital como un reflejo de la cultura mosaico que describió Moles (1978, citado en Caro 2012). Ambas comparten sus principales características: la fragmentación de su discurso entendida como la falta de coherencia en su forma, autoría o contenido. Esta fragmentación viene consolidada ante la cantidad masiva de información identitaria que reciben los sujetos en las redes, que favorecen la fragmentación y la mezcolanza en la adscripción de elementos de identificación del yo. La otra característica definitoria es la asunción de contenidos provenientes de las grandes industrias culturales que forman parte constitutiva de esta formulación de red digital. Asumiendo contenidos de este origen se incorporan en la construcción del yo individual estructuras de grupos sociales determinantes para la comprensión de la estructura social y, a su vez, componentes corporativos y comerciales.

Otras perspectivas enfocan esta caracterización estructurante del medio a la formulación de la identidad en el medio digital desde el análisis de los conceptos de perdurabilidad y memoria. Desde los estudios culturales y de la comunicación, autores como Núñez Puente y García Jiménez (2008), basados en la noción de García Gutiérrez, trazan una comprensión de lo que es Internet con una dimensión social. García Gutiérrez (2005) defiende que la identidad colectiva está cimentada, entre otros factores, en la memoria, ya que el proceso de creación de una memoria colectiva genera una identificación grupal a través de la construcción de significados basados en la mitificación de un pasado común. A partir de este concepto, se puede entender Internet como

... un conglomerado tecnológico que es y dará cobijo a la memoria de la humanidad y que muestra una clara habilidad para homogeneizar, reducir y acelerar. Se postula como un espacio necesitado de una visión crítica que ponga de manifiesto las formas de monopolio y colonización cultural y de conocimiento que se difuminan en su interior. Desde donde se podrán valorar adecuadamente las interrelaciones entre identidad, conocimiento y memoria” (Núñez Puente y García Jiménez, 2008, p. 46).

De esta forma expresan la necesidad de una visión crítica sobre la interacción que construye las identidades digitales, puesto que las características intrínsecas del espacio social digital son determinantes para comprender los códigos identitarios que allí se generan, y a su vez, los usos y propiedades que tienen estas formas de identificación comunes en nuestra actualidad.

\section{La producción y el consumo de contenido digital como intercambio identitario}

Como se ha señalado, el aspecto de la perdurabilidad y la memoria es uno de los componentes que más incertidumbre ha generado en los estudios sobre la interacción 
social en Internet. Los elementos identitarios digitalizados son perdurables en tanto que los datos, una vez expuestos online, difícilmente se pueden borrar, ya sea por los propios formatos o incluso por la memoria colectiva digital -como capturas de pantalla, descargas de foto, audio o vídeo, subida a la nube por otros usuarios, etc.-, pero tienen un factor caduco relevante que es el que ofrece el exceso de información volcada. Zafra (2015) pone el foco de atención en este aspecto: se vuelca tanta información que expresa quiénes y cómo somos que se pierde en la abundancia. El exceso de producción de imágenes y su consumo, así como la intervención de la maquinaria organizadora y contenedora de esa información visual, crea parte de la necesidad identitaria de los sujetos en el mundo digital. Las imágenes y yoes en redes sociales son una forma de creación del yo en sí misma, donde la construcción identitaria se nutre ya no únicamente de la adscripción a un grupo, sino de las imágenes que ese grupo proyecta en unos espacios delimitados y gestionados de forma ajena. El sujeto se construye como un producto intercambiable que genera tráfico online, visibilidad, posicionamiento, y por tanto, capital. Proporciona estatus y reconocimiento como parte de la estructuras de yoes que construyen ese espacio, produciendo la satisfacción de una imagen personal integrada. Por lo que esta organización del sistema online premia la conversión de sujetos en objetos consumibles. Para esta autora el funcionamiento del espacio digital marca la propia creación y consumo de contenidos, porque los intereses económicos son intrínsecos a la estructura digital (Zafra, 2015). Sin embargo, la flexibilización estructural que el ámbito digital supone para el intercambio económico ha hecho que la relación clásica entre producción y consumo cambie sustancialmente.

\subsection{La prosumición y el yo como creador de capital}

Esta nueva forma de relacionarse entre lo que se es, y lo que se mira, produce unas relaciones entre consumidor y producción muy diferentes a las que se habían visto hasta ahora. Es lo que Jenkins (2008) describe como convergencia: "flujo de contenido a través de múltiples plataformas mediáticas, la cooperación entre múltiples industrias mediáticas y el comportamiento migratorio de las audiencias mediáticas dispuestas a ir casi a cualquier parte en busca del tipo deseado de experiencias de entretenimiento" (p.14). En esta convergencia los productores y los consumidores se relacionan de maneras muy diversas, inimaginables hasta ese momento. Para Jenkins (2008) "los consumidores están aprendiendo a emplear estas diferentes tecnologías mediáticas para controlar mejor el flujo de los medios y para interaccionar con otros consumidores" (p. 28). Una consecuencia de este efecto es la perspectiva de los consumidores para generar y/u obtener flujos dinámicos, libres de ideas y contenidos. Es decir, flexibilizar la línea entre consumidor y productor a través de unos medios participativos, que se encuentren menos sostenidos en la pasividad. Esta división moldeable del consumidor y productor de contenido digital ha favorecido la denominación de un nuevo actor en este intercambio, la figura del prosumidor. El concepto de prosumidor fue acuñado por McLuhan y Nevitt en el año 1972 (2008) y se originó como la unión de los conceptos productor y consumidor haciendo así referencia a que "la tecnología electrónica permitiría al consumidor asumir simultáneamente los roles de productor y consumidor de contenidos" (2008, p. 35).

La conceptualización del prosumidor no se asocia únicamente a la idea de producción remunerada que se ejerce de manera profesional, sino que engloba también la pro- 
ducción de contenido ligada al ocio y a las relaciones afectivas y sociales que se tienen con los otros digitales, ya tengan un lazo en la vida off-line o no. Zafra (2011) relata esa unión de vidas a través de Internet como un cuarto propio que se interconecta a través de las tecnologías digitales, haciendo una analogía con el cuarto propio que expone Virginia Woolf. A diferencia de este, la autora defiende que este cuarto interconectado no presenta una herencia patriarcal, y que se muestra con las mismas posibilidades de utilización para ambos géneros. Para la autora, la prosumición está muy ligada al trabajo doméstico históricamente asociado a -y asumido por- las mujeres. Para comprender la relación entre ambos conceptos se ha de comprender

... que por mucho tiempo el trabajo doméstico se situó en el corazón del consumo, y que las aportaciones feministas enfatizaron la falta de neutralidad en la consideración del vínculo entre el consumo y la producción, como fruto simultáneo de la actividad económica capitalista. De igual manera, también se reclamó una visibilización y revalorización de lo hecho entre las paredes de la casa: el trabajo familiar, afectivo, de atención, cuidado y mantenimiento de las vidas cercanas, sin ningún tipo de contraprestación salarial, salvo la que los mitos y leyendas se han ocupado de reiterar como suficiente: pago con <amor>" (Zafra, 2011, p. 5).

La autora nos pone sobre aviso de que el concepto de prosumición para hablar de identidades digitales no es un concepto neutro ni está desligado de una realidad estamentada, capitalista y patriarcal. Zafra defiende que la producción y el consumo simultáneo de elementos identitarios digitales están situados en el contexto sociohistórico. Nuestra reinterpretación de ellos a la hora de producirlos puede crear imágenes e imaginarios emancipadores o rupturistas, o por el contrario perpetuadores de esas estructuras de poder.

\section{El Yo-objeto y su relación con la objetualización de la mujer}

La figura del prosumidor de contenido digital construye su propio yo consumiendo elementos digitales identitarios y ese resultado puede ser consumido por otros para la construcción de su propia identidad. Como se ha mencionado con anterioridad, la construcción de un yo digital implica cosificar nuestras acciones, convertir en objetos lo que somos en nuestros perfiles de usuario y convertirlo en un yo-objeto con el que podemos experimentar, o que se puede manipular y cambiar, e interactuar así con otros usuario objeto en el mismo medio (Fernández, 2012).

Esta característica es común a la interacción social en el medio digital, pero la objetualización no afecta a todas las personas por igual. Como detallan Fredrickson y Roberts (1997) en su texto "Objectification Theory" la objetivización sobre los sujetos que ellos describen es un fenómeno que solo afecta a mujeres. Cuando se objetualiza a las mujeres, éstas son tratadas únicamente como cuerpos sin agencia ni personalidad que únicamente existen por y para el placer de otros. Esta forma de convertir a las mujeres en objetos ha sido fuertemente estudiada en ámbitos como la publicidad y en los contenidos visuales de los medios de comunicación, pero más allá de la sexualización y el uso de las mujeres por parte de los mass media, la objetivización también se da en la interacción personal cotidiana de las mujeres (Fredrickson y Roberts, 1997). 
La mirada objetivadora es considerada una forma de violencia. No solo promueve la idea de que las mujeres son seres-para-otros (Lagarde, 2008), sino que implican unas consecuencias negativas bastante graves para la vida de las mujeres. La consecuencia que más repercusión tiene para las mujeres es que la objetivización incita a adquirir una visión cosificadora de sí mismas. Las mujeres crecen en un entorno que les empuja a aceptar unos imaginarios corporales específicos. Ello conlleva a asumir esas presiones externas como una preocupación constante acerca de su físico y a la auto-objetivación de sus cuerpos. Otra consecuencia derivada de la auto-cosificación, son las consecuencias en la salud mental que produce la percepción cosificadora del propio cuerpo, ya que a causa de la objetivación las mujeres experimentan, entre otros, sentimientos de humillación, vergüenza, ansiedad y bajo conocimiento del propio cuerpo y sus fluctuaciones internas, tal como analizaron Fredrickson y Roberts (1997).

Existe literatura científica reciente que asocia la objetualización del cuerpo de las mujeres con un mayor malestar en la autopercepción de estas en la interacción desde las redes sociales digitales. Por mencionar algunos ejemplos, en un estudio llevado a cabo por Vandenbosch y Eggermont (2012), de la Facultad de Ciencias Sociales de la Universidad KU Leuven, realizaron un cuestionario a adolescentes de entre 13 y 18 años para medir la auto-objetivación y la internalización de mensajes cosificadores del cuerpo de las mujeres difundidos desde los medios de comunicación y las redes sociales. En los resultados de su análisis manifiestan que los adolescentes están altamente expuestos a mensajes cosificadores desde los medios de comunicación siendo las redes sociales el medio de comunicación más consumido por la muestra, por encima de la televisión o la prensa. A su vez las adolescentes tenían una mayor vigilancia sobre su aspecto físico a lo largo del día que sus compañeros varones, y reconocían hacer una comparación exhaustiva de sus cuerpos con los cuerpos de otras mujeres que veían en los medios de comunicación consumidos.

Otros estudios muestran que el uso y la interiorización de redes sociales cambia según el género del usuario. En una investigación de la Universidad de Illinois se realizó un estudio (Bond, 2009) a través de un cuestionario a una población de jóvenes adultos con un tamaño muestral de 137, 61 hombres y 76 mujeres. Su objetivo era medir las diferencias y similitudes entre el contenido que compartían hombres y mujeres en redes sociales, y las impresiones personales hacia el contenido propio. El autor destacó en sus resultados que las mujeres comparten más información personal que sus coetáneos varones, la información compartida por las mujeres era propensa a ser sobre familiares, amigos y entorno cercano que el contenido compartido por los hombres. A su vez, ellas exponen también más contenido de expresión sexual que los hombres. Estos resultados plantean que la auto-objetivación del yo virtual en mujeres está más relacionada con la sexualización, y que las mujeres tienen la tendencia a construir un yo virtual más completo en información personal y expresión afectiva.

Estos estudios ejemplifican cómo esa visión cosificadora esencialmente violenta para las mujeres repercute en la percepción y construcción del yo digital, ya que no se diferencia radicalmente entre el proceso de auto-objetivación necesario para la identidad digital y la objetivización de las mujeres.

A pesar del riesgo de este tipo de violencia para las mujeres, existen propuestas para la subversión de la mirada cosificadora en el proceso de creación de la identidad digital a través de la transgresión de significados, todas las propuestas existentes surgen desde el ciberfeminismo. Las autoras que han estudiado en 
profundidad la perspectiva y práctica feminista en el ámbito virtual, también llamado ciberfeminismo, señalan que la mayor necesidad se encuentra en dotar lo digital de significados emancipadores y empoderadores, para así construir una nueva significación de los contenidos, y por ende, de las identidades que se construyan en este ámbito.

Únicamente desde la perspectiva feminista encontramos las claves de un análisis capaz de discernir las implicaciones que la cosificación del yo pueda tener para las mujeres. Del mismo modo, solo a través de la praxis feminista online se podrá obtener una mirada alternativa a la actualmente existente. El feminista online "deja traslucir el deseo persistente de informar el mundo virtual de una agencia y subjetividad femenina. Este deseo permanente, presente en las últimas aportaciones teóricas, propicia la creación de nuevos sujetos femeninos" (Núñez Puente, 2008, p. 121).

\section{Conclusiones}

A través de las diferentes visiones teóricas sobre la identidad digital se puede deducir que, indistintamente del paradigma teórico, esta es una cuestión que genera mucho interés y producción científica. Esta visión amplia permite alejarnos y reflexionar sobre un tema que es necesario abordar a partir de un análisis crítico y pormenorizado. Como se ha explicado con detenimiento, la identidad digital no se puede comprender sin la visión cosificadora de los elementos identitarios. Resulta relevante remarcar que la visión del yo-objeto se contextualiza en un marco de características propias, por lo que no es posible su comprensión sin una inmersión profunda en las particularidades del contexto. A pesar de sus diferenciaciones esenciales, las distintas posturas teóricas sobre la identidad suelen incidir en la importancia de la estructura social del individuo desde la que se construye su identidad, ya sea desde una posición más focalizada en las formas de relación e interacción de agentes sociales, o en las formas de significación en las estructuras macrosociales.

Es por esto que se debe pensar el entorno digital como un espacio social donde las estructuras e interrelaciones construyen las identidades de los individuos. Así como esas identidades servirán como elementos identitarios a otras formaciones en un ejercicio de construcción colectiva y multidireccional. Es, por tanto, un espacio social de construcción colectiva con un rasgo de flexibilidad notable en comparación con el modelo dador/recibidor-productor/consumidor.

Aun así la cosificación no es neutra ni inocua. Fuera del ámbito digital, el cuerpo de las mujeres ha sido objetualizado como forma de violencia y control hacia la población femenina, produciendo una conceptualización del yo en las mujeres altamente basada en la idea del ser para otros. A pesar de que la autoobjetivación en la identificación digital es intrínseca al ámbito online, puede suponer un alto riesgo de que se perpetúe o incremente la visión cosificadora hacia los cuerpos de las mujeres. Y por ende, se aleje de creación de un yo sin una visión patriarcal. Finalmente señalamos la necesidad de una lectura y de un análisis feminista crítico sobre esta forma de construcción de identidades. E1 análisis feminista debe permitir comprender en profundidad el impacto para las mujeres de esta objetivación de la identidad personal, así como la elaboración de resistencias a la mirada patriarcal cosificadora. 


\section{Referencias}

Bond, B (2009). He Posted, She Posted: Gender Differences in Self-disclosure os Social Networks Sites. Rocky Mountain Communication Review, 6 (2), 29-37.

Caro, L. (2012). La encarnación del yo en las redes sociales digitales. Revista Telos. Cuadernos de Comunicación e Innovación. Identidad Digital, 91, 59-68.

Fernández, A. (2012). De la auto-objetivación como fuente de control: User profiling. Revista Telos. Cuadernos de Comunicación e Innovación. Identidad Digital, 91, 69-78.

Fredrickson, B. \& Roberts, T. (1997). Objectification theory: Toward understanding women's lived experiences and mental health risks. Psychology of women quarterly, 21(2), 173-206.

García Jiménez, A, y Núñez Puente, S. (2008). Apuntes sobre la identidad virtual de género. Feminismo/s: Revista Del Instituto de Investigación de Estudios de Género de La Universidad de Alicante, 11, 41-58.

García, A. (2005). Fijaciones: estudios críticos sobre políticas, culturas y tecnologías de la memoria. Madrid: Biblioteca nueva.

Goffman, E., Perrén, H. y Setaro, F. (1971). La presentación de la persona en la vida cotidiana (Vol. 60). Buenos Aires: Amorrortu.

Hernando, A. (2012). La fantasía de la individualidad. Sobre la construcción sociohistórica del sujeto moderno. Madrid: Katz Editores.

Hogg, M., Terry, D. \& White, K. (1995). A tale of two theories: A critical comparison of identity theory with social identity theory. Social psychology quarterly, 58(4), 255-269.

Islas-Carmona, J. (2008). El prosumidor. El actor comunicativo de la sociedad de la ubicuidad. Palabra clave,11(1), 29-39.

Jenkins, H. (2008). Convergence culture: La cultura de la convergencia en los medios de comunicación. Barcelona: Paidós.

Lagarde, M. (2008). Antropología, feminismo y política: violencia feminicida y derechos humanos de las mujeres. Retos teóricos y nuevas prácticas, 209-240.

Núñez Puente, S. (2008). Una exploración de la praxis feminista en España: nuevas tecnologías y nuevos espacios de relación desde el ciberfeminismo. Feminismo/s: Revista Del Instituto de Investigación de Estudios de Género de La Universidad de Alicante, 11, 109-123.

Peris, R. y Agut, S. (2007). Evolución conceptual de la identidad social. El retorno de los procesos emocionales. Revista Electrónica de Motivación Emoción, 26-27.

Serpe, R. \& Stryker, S. (2011). The symbolic interactionist perspective and identity theory. En Handbook of identity theory and research (pp. 225-248). New York: Springer.

Tajfel, H. (1984). Grupos humanos y categorías sociales. Barcelona: Herder.

Vandenbosch, L. \& Eggermont, S. (2012). Understanding sexual objectification: A comprehensive approach toward media exposure and girls' internalization of beauty ideals, self-objectification, and body surveillance. Journal of Communication, 62(5), 869-887.

Zafra, R. (2011). Un cuarto propio conectado. Feminismo y creación desde la esfera públicoprivada online. Asparkía. Investigació feminista, 22, 115-129.

Zafra, R. (2015). La censura del exceso: apuntes sobre imágenes y sujeto en la culturared. Paradigma: revista universitaria de cultura, 18, 17-20. 